\title{
Unidades da paisagem da bacia do Río das Almas, microrregião de Ceres/GO
}

\author{
Landscape Units of the Rio das Almas Basin, Microregion Ceres/GO
}

\section{Maria Gonçalves da Silva Barbalho ${ }^{1}$ \\ Antônio Cezar Leal ${ }^{2}$ \\ João Osvaldo Rodrigues Nunes ${ }^{3}$ \\ Cristiane Gonçalves de Moraes ${ }^{4}$ \\ Josana de Castro Peixoto 5}

\footnotetext{
1 Professora Doutora do Programa de Pós-graduação em Sociedade, Tecnologia e Meio Ambiente (PPG STMA - Centro Universitário de Anápolis, Goiás.

2 Professor Doutor do Departamento de Geografia - FCT/UNESP e pesquisador PQ/CNPq.

3 Professor Doutor do Departamento de Geografia - FCT/UNESP e pesquisador PQ/CNPq.

4 Professora Mestre do curso de Ciências Biológicas do Centro Universitário de Anápolis, Goiás.

5 Professora Doutora do Programa de Pós-graduação em Sociedade, Tecnologia e Meio Ambiente (PPG STMA- Centro Universitário de Anápolis, Goiás e da Universidade Estadual de Goiás.
}

RESUMO: O objetivo deste estudo foi identificar os conflitos do uso da terra com base na compartimentação morfopedológica, delimitadas a partir da sobreposição temática dos elementos do meio físico e uso e ocupação da terra, com finalidade de subsidiar o planejamento do uso da terra na bacia hidrográfica do Rio das Almas, na área abrangida pela Microrregião de Ceres, estado de Goiás. Os procedimentos envolveram trabalho de campo, classificação de imagens e geração de mapas. Os resultados permitiram identificar a incidência de focos de erosão linear nos quatro compartimentos morfopedológicos, em relação aos fatores geológicos, geomorfológicos, pedológicos e padrão de drenagem.

Palavras-chaves: Morfopedologia. Erosão linear. Goiás.

ABSTRACT: The aim of this study was to identify land use conflicts based on morphopedological compartmentalization, delimited from the thematic overlap of the elements of the physical environment and land use and occupation, with the purpose of subsidizing the land use planning in the basin. River das Almas, in the area covered by the Ceres Microregion, state of Goiás. The procedures involved field work, image classification and map generation. The results allowed to identify the incidence of linear erosion foci in the four morphopedological compartments, in relation to the geological, geomorphological, pedological factors and drainage pattern.

Keywords: Morphopedology. Linear erosion. Goiás

Sumário: Introdução - 1 Materiais e Métodos - 2 Resultados e Discussões - Considerações Finais - Referências

\section{INTRODUÇÃO}

Na bacia hidrográfica do Rio das Almas, no trecho situado na Microrregião de Ceres, estado de Goiás, no qual é área de estudo, as paisagens foram descritas por FAISSOL (1952) como uma área florestada de Cerrado em Goiás, conhecida como Mato Grosso de Goiás, que cobria indistintamente vales, encostas e topos elevados, com área aproximada de $20.000 \mathrm{~km}^{2}$ na região central do Estado de Goiás, Brasil.

Não eram uniformes e por isso foram classificadas como matas de primeira classe, associadas aos melhores solos, que ocorriam no vale do Rio das Almas e de seus afluentes, nas quais se praticavam as 
culturas e as melhores invernadas, além de matas de segunda classe que surgiam próximas às cabeceiras de drenagem, nos altos dos chapadões ou nas zonas limítrofes entre matas de primeira e os cerrados, utilizadas frequentemente com pastagem, uma vez que o solo da mata de segunda classe se esgotava rapidamente, quando cultivado (BARBALHO, 2017).

A primeira expansão agrícola que ocorreu na região do Mato Grosso de Goiás, cuja dinâmica e o modelo de uso da terra se assemelha ao que ocorreu na Mata Atlântica com a expansão da economia cafeeira, foi associada à produção de outros grãos e auxiliada pelo trabalho dos mateiros na derrubada e exploração florestal para fins agrícola e antecede a grande produção do agronegócio, atualmente dominante nas áreas de cerrado stricto sensu (DUTRA e SILVA, 2017).

Cerca de 80 anos depois de iniciado o processo com as frentes pioneiras (WAIBEL, 1948), constatase a redução expressiva da cobertura vegetal. Das matas e dos cerrados, preteridos no início do processo de ocupação, que cobriam extensas áreas na bacia hidrográfica do rio das Almas, na Microrregião de Ceres (GO), atualmente existem apenas fragmentos (BARBALHO et al. 2015) e as mesmas foram substituídos por pastagens e lavouras para a produção de grãos, sobretudo soja e milho e, mais recentemente, com a cana de açúcar que dominam nas paisagens.

Esse avanço da cana de açúcar sobre áreas produtoras de grãos pode levar a incorporação dos remanescentes de Cerrado ao processo produtivo (SILVA e MIZIARA, 2011; BARBALHO et al., 2015), bem como à degradação ambiental pelo uso indiscriminado de agroquímicos, utilização e descarte da vinhaça, contaminação dos solos, dos recursos hídricos, erosão e compactação dos solos entre outros impactos, com consequências negativas inevitáveis ao meio ambiente. Para Turner (1989) esse cenário é resultado da ação humana que transformou a região ao longo da história.

Diante do exposto, este artigo teve como objetivo identificar os conflitos no uso atual da terra com base na compartimentação morfopedológica, que permite identificação do padrão espacial, para subsidiar o planejamento do uso da terra na Microrregião de Ceres, no trecho abrangido pela bacia hidrográfica do rio das Almas. Foram consideradas a incidência de focos erosivos lineares, de médio a grande porte, em relação aos fatores geológicos, geomorfológicos e ao padrão de drenagem, a partir da sobreposição desses componentes, utilizando imagens orbitais e um Sistema de Informações Geográficas (SIG).

A delimitação espacial das unidades de paisagens ou compartimentos morfopedológicos (CASTRO e SALOMÃO, 2000), com a sobreposição temática dos elementos do meio físico e biótico permitem o reconhecimento da interação desses componentes, bem como as inter-relações temporais e espaciais específicas entre a sociedade e a natureza, constituindo um documento de síntese para o planejamento de uso e ocupação das terras.

\section{MATERIAIS E MÉTODOS}

A bacia hidrográfica do rio das Almas, na área da Microrregião de Ceres (GO), localiza-se entre as coordenadas geográficas $17^{\circ} 52^{\prime} 53^{\prime \prime}$ de latitude sul e 51 42' 52" de longitude oeste, possuindo aproximadamente $10.246 \mathrm{~km}^{2}$, distribuídos por territórios de 21 municípios, com destaque para as cidades de Goianésia, Ceres Rialma e Barro Alto. As cidades de Ceres e Rialma estão situadas nas barrancas do rio das Almas.

A rede hidrográfica pertence à bacia hidrográfica do Rio Tocantins, sendo os principais afluentes os rios: Sucuri, Uru e Verde, sua nascente localiza-se no Parque Estadual da Serra dos Pirineus, com altitude aproximada de 1.200 metros e a sua foz no lago de Serra da Mesa com atitude de 450 metros. 
O clima é do tipo tropical, enquadrado na classe Aw definida por Köeppen, apresenta inverno seco e verão chuvoso. O maior índice pluviométrico ocorre entre os meses de outubro e abril e o período de estiagem entre maio e setembro. O volume pluviométrico médio anual é de aproximadamente $1.800 \mathrm{~mm}$ e a temperatura média no inverno varia entre $10^{\circ} \mathrm{C}$ e $27^{\circ} \mathrm{C}$ e no verão varia entre $18^{\circ} \mathrm{C}$ e $35^{\circ} \mathrm{C}$, podendo chegar até $38^{\circ} \mathrm{C}$ (CARDOSO, et al., 2014; CIANCIARUSO, et al., 2005). A vegetação original é caracterizada pelas Formações Florestais, formações Savânicas e formações Campestres (RIBEIRO e WALTER, 1998).

Os estudos desenvolvidos por Barbalho (2017) sobre a bacia hidrográfica do Rio das Almas, na Microrregião de Ceres, mostraram que região possui uma população de cerca de 231.230 habitantes e densidade demográfica de 17,44 habitantes por $\mathrm{Km}^{2}$. A área ocupada pelos municípios é de $13.253,36 \mathrm{~km}^{2}$ e dos 22 municípios que estão inseridos na Microrregião, apenas um não faz parte da bacia hidrográfica do rio das Almas (Guarinos) e cinco não estão totalmente na área dessa bacia hidrográfica (Nova América, Itapaci, Pilar de Goiás, Barro Alto e Goianésia).

A ocupação humana na Microrregião de Ceres, na bacia hidrográfica do rio das Almas, é maior nas áreas urbanas representando 83,27\%, enquanto a população rural responde por $16,73 \%$. Os municípios que apresentam o maior número de habitantes (acima de 20.000 habitantes) são: Goianésia (59.549), Itapuranga (26.125) e Ceres (20.722).

A base econômica dos municípios que compõe a bacia hidrográfica do rio das Almas, na Microrregião de Ceres, está alicerçada na agropecuária, principalmente a criação extensiva de gado e dos cultivos da soja, milho e a cana de açúcar. Já a economia urbana se baseia em atividades comerciais e de prestação de serviços para atender as demandas locais.

Tendo em vista o objetivo da pesquisa de identificar os conflitos no uso atual da terra com base na compartimentação morfopedológica para subsidiar o planejamento territorial na Microrregião de Ceres, na bacia hidrográfica do Rio das Almas foram realizadas as etapas metodológicas descritas a seguir:

a) Elaboração do mapa de cobertura e uso da terra, na escala 1:50.000 (de semi-detalhe) - Foram utilizadas as Imagens Sentinel disponibilizadas pelo Serviço Geológico dos Estados Unidos (U.S.G.S. - United States of Geological Survey) do ano de 2016. A legenda foi adaptada da proposta do Instituto Brasileiro de Geografia e Estatística (IBGE, 2013) e dos remanescentes do Cerrado, adotou-se as formações, conforme Ribeiro e Walter (1998).

No Programa SPRING/5.2 foi realizada a segmentação das imagens Sentinel, utilizando o algoritmo de crescimento de regiões, que rotula cada "pixel" como uma região distinta até que toda imagem seja segmentada, com o limiar de similaridade 5 e área do pixel 10 (BLASCHKE e KUX, 2005; BECKER, et al., 2012; BLASCKE et al., 2014). O procedimento de classificação baseado em objetos está representado na Figura 1. 
Figura 1 - Processo de Segmentação

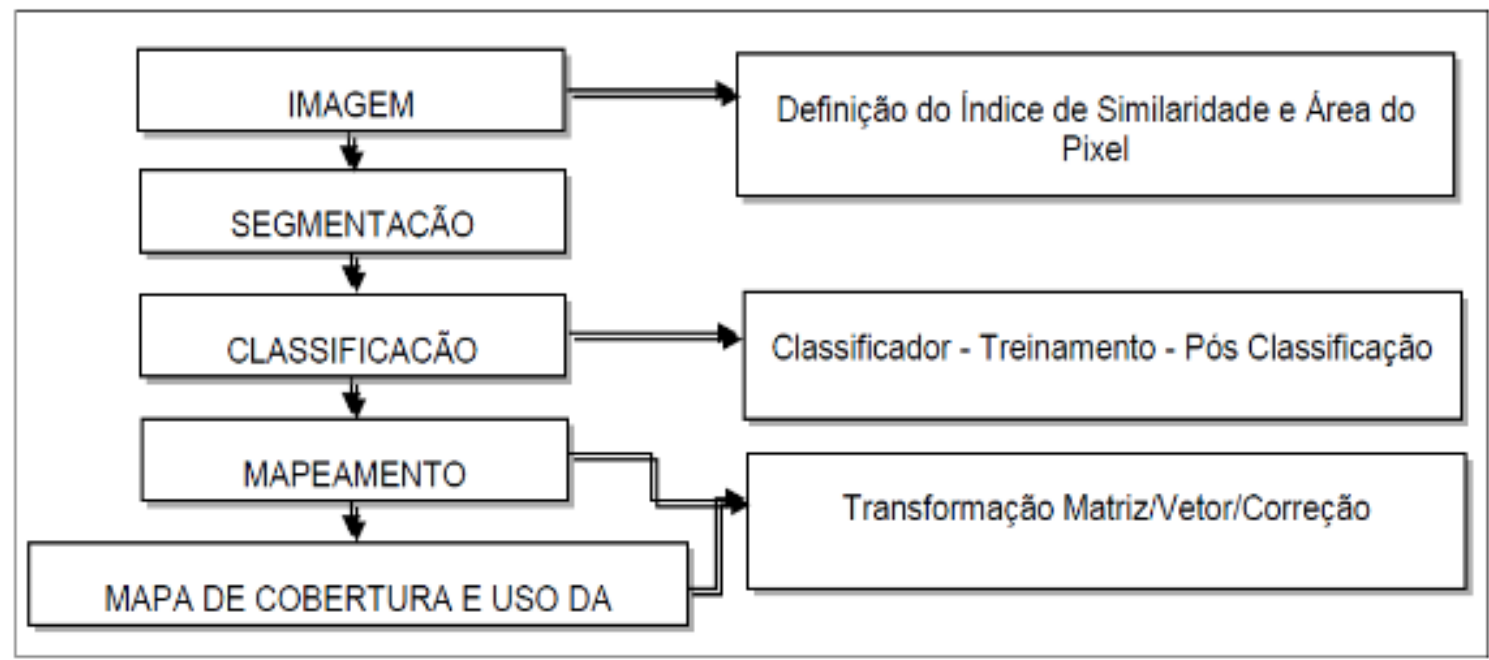

Fonte: Barbalho (2017).

Para classificar as regiões formadas no processo de segmentação foi utilizado o algoritmo Battacharya que requer interação do usuário para identificar as regiões. Os erros de classificação foram corrigidos em edição vetorial e interpretação visual.

Foram realizadas duas campanhas de campo para validação do mapa de cobertura e uso do solo, sobretudo para identificação das fitofisionomias, com base em roteiros que abrangeram parte da área em estudo, por representatividade. Com o Global Positioning System (GPS), registrou-se no campo, os pontos que permitiram as correções do mapeamento. Foram tiradas várias fotos dos usos e fitofisionomias, com o fim de ilustração dos padrões de cobertura.

b) Mapas de Geologia, Geomorfologia e Solos - Foram compilados do IBGE (2013) na escala $1 / 250.000$

c) Elaboração dos modelos digitais de elevação (MDE) hipsometria e declividade a partir das imagens Shuttle Radar Topographic Mission (SRTM), resolução de 30m. (1) Mapa hipsométrico - a área foi compartimentada em oito unidades altimétricas com intervalos de 100 metros, considerados adequados para representar os conjuntos topográficos, que relevaram 8 as unidades geomorfológicas e (2) Mapa de declividade definiu-se as classes segundo Ramalho Filho e Beek (1995), nos seguintes intervalos: Plano (0-3\%); Suaveondulado (3-6\%); Moderadamente Ondulado (6-12\%); Ondulado (12-20\%); Forte ondulado (20-45\%) e montanhoso $(>45 \%)$.

d) Elaboração do mapa da rede de drenagem - utilizando as imagens RapidEye, foi digitalizada a drenagem, na escala 1:25.000 (na tela do computador). O processo de digitalização manual constitui uma das etapas que exige maior tempo e atenção, para que os resultados sejam os mais precisos possíveis.

e) Elaboração do mapa de focos erosivos - foram utilizadas as imagens de alta resolução do Google Earth. O critério utilizado na interpretação foi a presença de incisões no relevo, expondo material de cores mais claras. Não foi possível identificar os tipos de erosão (ravinas ou voçorocas).

f) Delimitação das Unidades de Paisagem e/ou Compartimentos morfopedológicos (Castro \& Salomão, 2000) - a proposição geral é a divisão da área em unidades homogêneas definidas a partir da análise e interpretação conjunta dos aspectos referentes a geologia, relevo, hipsometria, declividade, hidrografia e uso da terra. 
g) Cruzamento do mapa de compartimentos morfopedológicos com mapa de focos erosivos e de cobertura e uso da terra.

h) Interpretação quanto às relações entre focos erosivos, seus condicionantes do meio físico e biótico e de uso e cobertura.

\section{RESULTADOS E DISCUSSÕES}

A bacia hidrográfica do rio das Almas, na Microrregião de Ceres, apresenta uma diversidade de paisagens resultante dos atributos como: geologia, geomorfologia, hipsometria, declividade, vegetação, hidrografia e uso e ocupação da terra (figuras 2, 3, 4 e 5). Em termos geológicos, a bacia hidrográfica, está inserida na Província do Tocantins que é uma unidade tectônica Neoproterozóica desenvolvida durante a colagem orogênica brasiliana.

Figura 2 - Mapas de Geologia e Geomorfologia

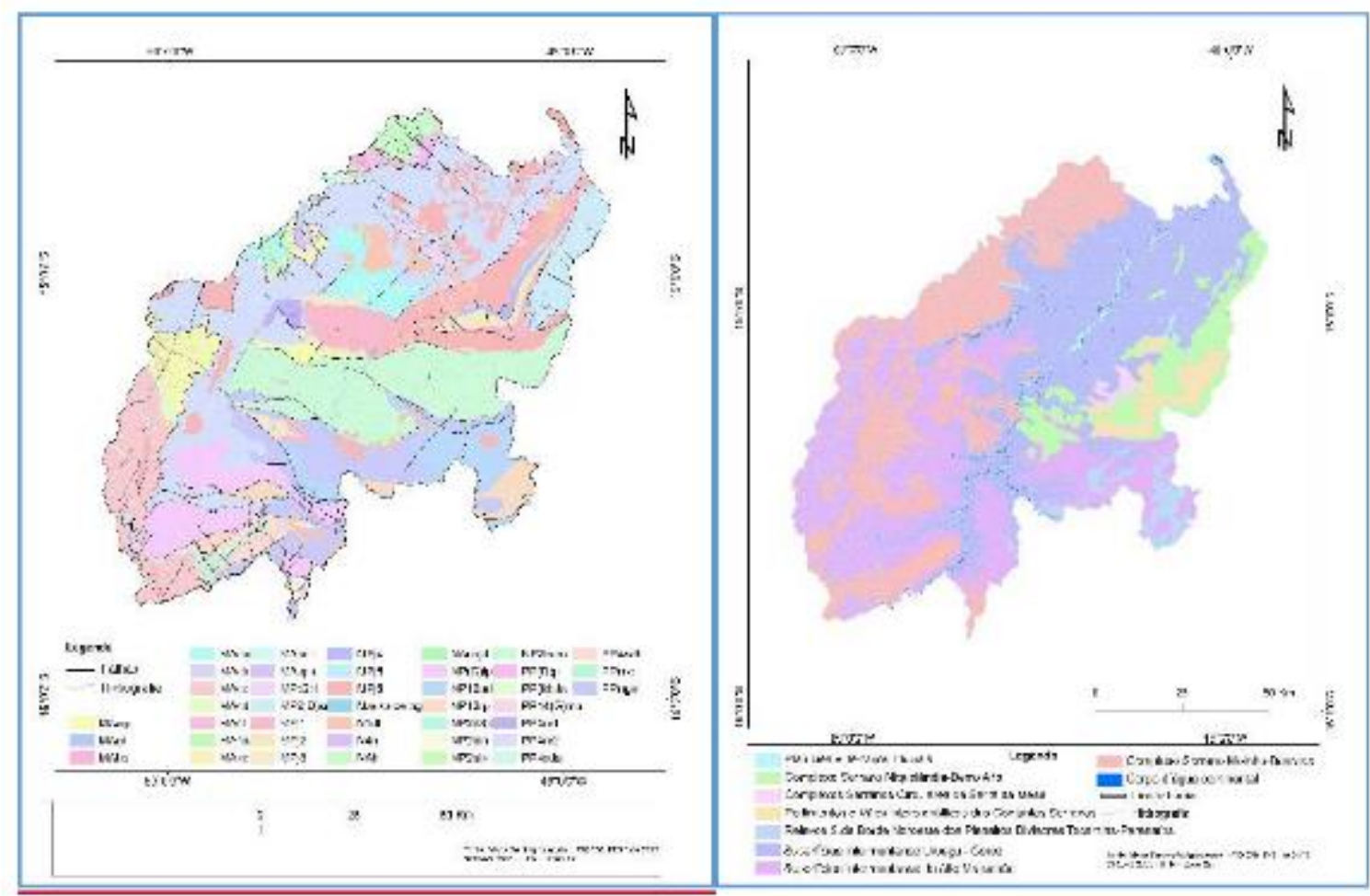

Fonte: Barbalho (2017). 
Figura 3 - Mapas de Solos e Declividade

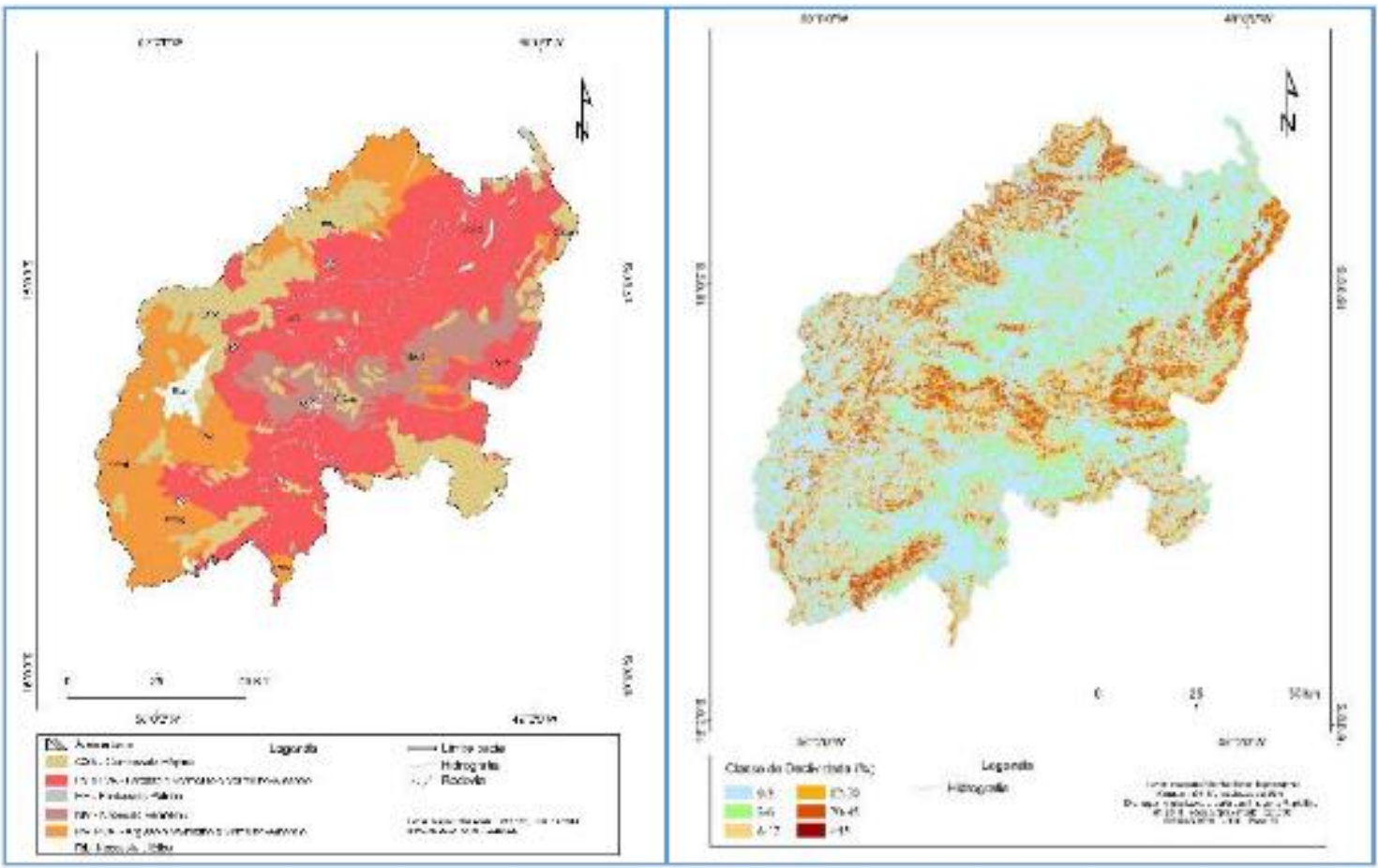

Fonte: Barbalho (2017).

Figura 4 - Mapas Hipsometria e Drenagem

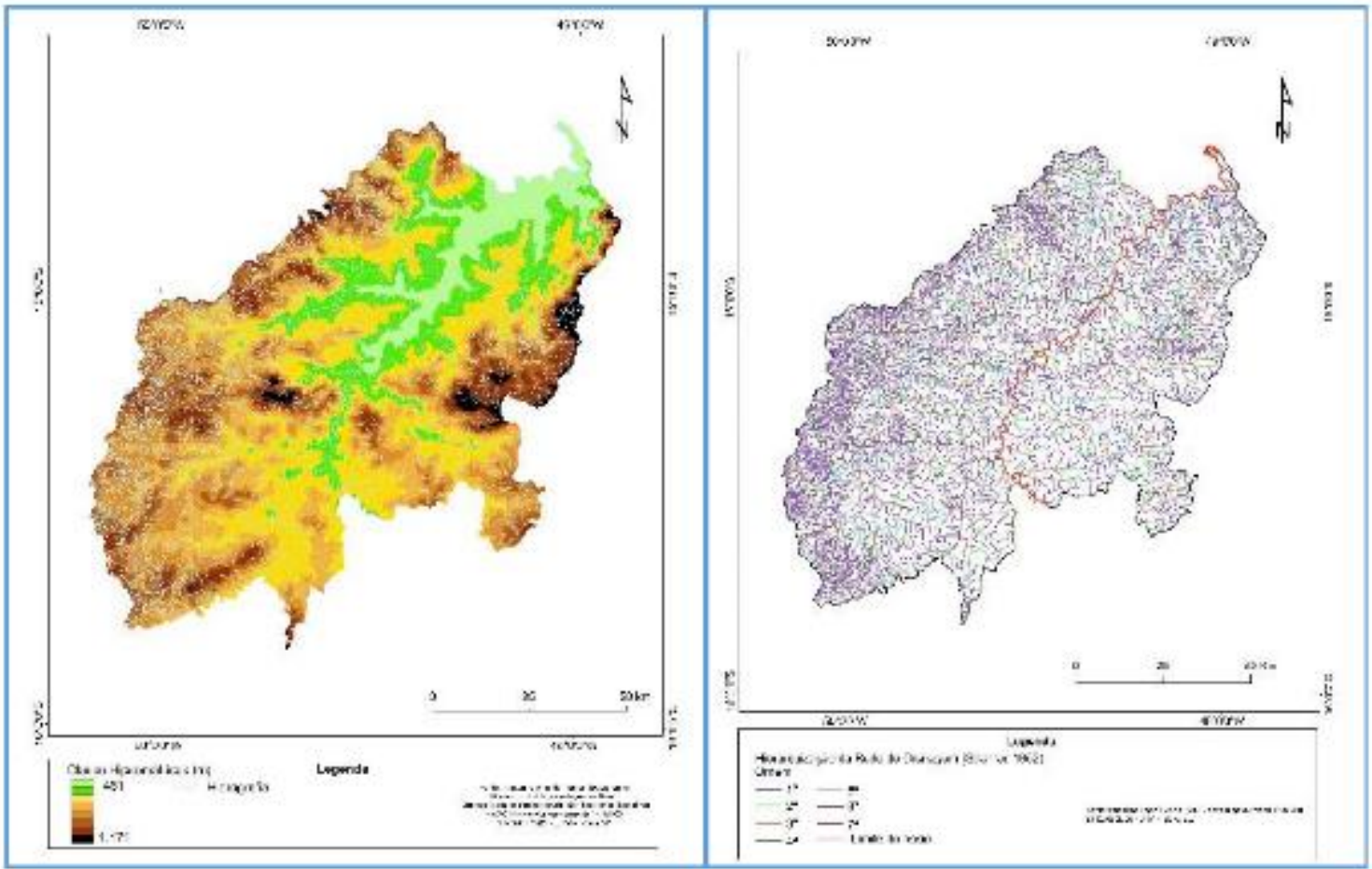

Fonte: Barbalho (2017). 
Figura 5 - Cobertura e uso da Terra

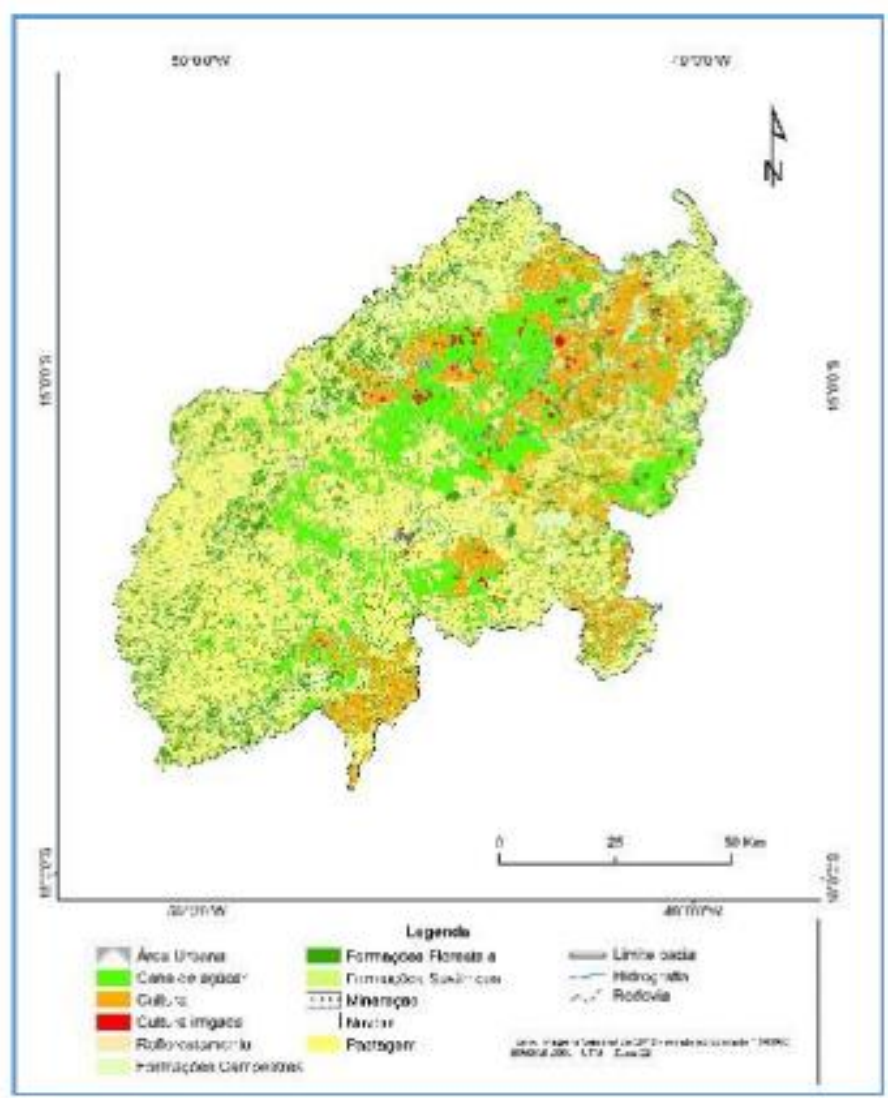

Fonte: Barbalho (2017).

A bacia hidrográfica do rio das Almas foi dividida por Lacerda Filho e Frasca (2008), nas faixas Brasília, Araguaia e Paraguai. Na área predomina a faixa Brasília, representada por litologias dos complexos Granulítico, Máfico-Ultramáfico, Grantito-Gnaissico, Greestone Belts e incluem suítes gabro dioríticas, intrusões graníticas e diques máficos, ultramáficos, e as do Arco Magmático de Goiás que é composto por rochas graníticas sintectônicas, sequência metavulcanossedimentar e granitos sin a tardi e pós-tectônicos.

Apresenta, ainda, áreas com formações superficiais mais recentes, representadas pelas Coberturas Detrito-lateríticas ferruginosas que compreende sedimentos aluviais ou coluviais constituídos por conglomerados oligomíticos com seixos de quartzito e lateritos autóctones com carapaças ferruginosas. E pelos Depósitos Aluvionares que se associam a rede drenagem e são pouco extensos e compreende acumulações de areia, cascalho e lentes de material silto-argiloso e turfa (LACERDA FILHO e FRASCA, 2008).

A bacia hidrográfica situa-se sobre a unidade geomorfológica denominada de Planalto Central Goiano, que reflete feições de relevos resultantes da exumação das estruturas dobradas decorrentes de vários ciclos tectônicos. Exibe dois compartimentos topográficos distintos. Um mais elevado com altimetrias entre 761 a 1471 metros, ocupando menor área, e outro rebaixado abrangendo cotas entre 461 a 761 metros, com maior área (MAMEDE et al., 1981).

O primeiro nível representa basicamente a planície e os terraços do rio das Almas e de seus afluentes, com cotas entre 461-561 metros; segundo e terceiro níveis, representados pelas superfícies intermontanas que acompanha e margeia o rio das Almas e seus tributários, com as áreas de colinas amplas, com cotas altimétricas de 561-761 metros; quarto, quinto e sexto níveis, com amplitudes de 761-900 metros, 
apresentam uma morfologia mais acidentada, sendo representados pelas serras que se localizam nas porções noroeste, nordeste, sudoeste e sudeste da área. O nível com cotas acima 1.000 metros correspondem aos planaltos divisores e ao Complexo Serrano no limite oeste, leste e sul da bacia.

A declividade confirma que a região apresenta relevo favorável à atividade agrícola, e que há grande potencial de expansão da cana de açúcar na microrregião, uma vez que predominam relevos com declives com até 12\% (78,50\% da área). Portanto, sem restrições de ordem topográfica para a mecanização. Os relevos fortemente ondulados a montanhoso representam pouco mais de $9 \%$ da área, restringindo-se às áreas das Serras.

A rede de drenagem da bacia hidrográfica apresenta o padrão geral dendrítico, embora apresente em algumas áreas feições que evidenciam o controle estrutural. O padrão dendrítico se desenvolve quando a rede de rede de drenagem se encontra sobre rochas com resistência homogênea com tributários espalhados por todas as direções do terreno.

O índice de dissecação varia entre baixa a muito alta o que permite inferir que algumas áreas apresentam maior suscetibilidade erosiva e que merecem cuidados específicos quanto aos usos. O rio das Almas é a drenagem principal e possui uma extensão de 468,88 Km, sendo um rio de $7^{\mathrm{a}}$ ordem segundo a classificação de Strahler. As classes de solos são: Argissolos, Cambissolos, Latossolos, Neossolos e Nitossolos ocupando respectivamente: $21,43 \% ; 20,28 \% ; 45,83 \% ; 1,72 \%$ e 8,95\%, (EMBRAPA, 2013). Os compartimentos morfopedológicos foram definidos e delimitados a partir da análise dos condicionantes físicos (geologia, geomorfologia, hipsometria, declividade, solos e de cobertura e uso do solo) predominantes e identificados por algarismo romano (figura 6 ).

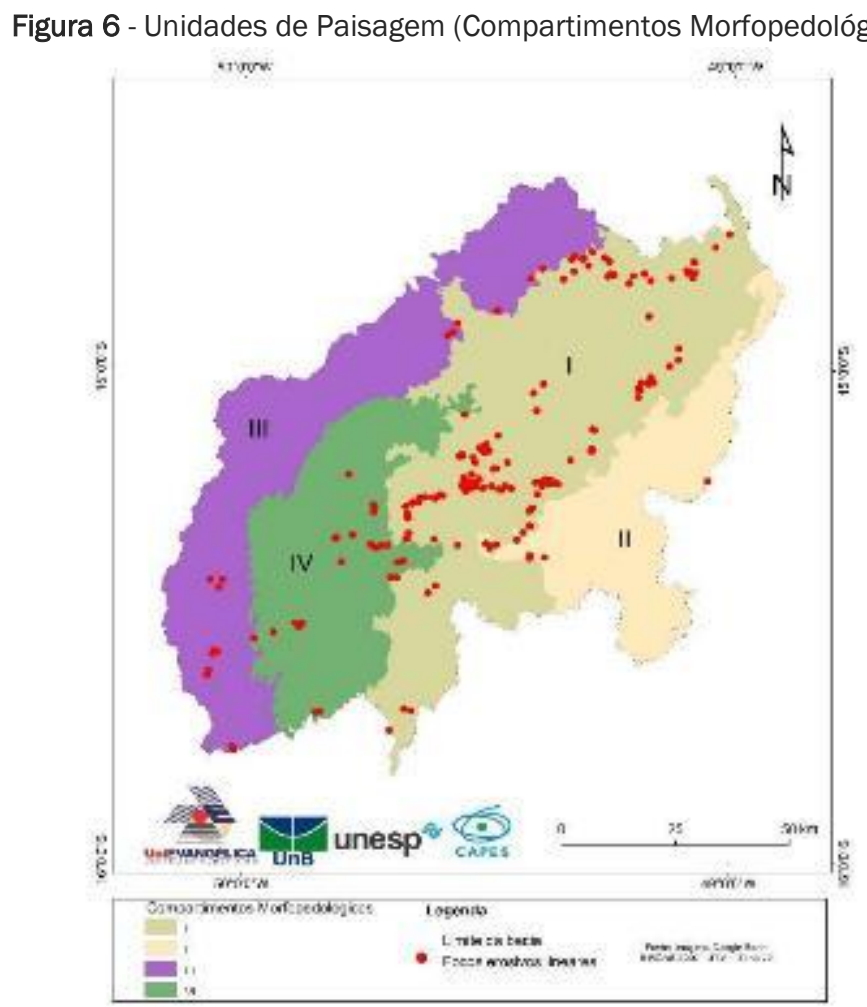

Fonte: Barbalho (2017).

Considerando estas características foram delimitadas quatro unidades de paisagem na bacia 
hidrográfica do rio das Almas, são elas:

a) Compartimento MP-I: A maior unidade delimitada representando 40,27\% da área. Localiza-se de norte a sul da bacia hidrográfica, basicamente na porção central. Exibe diferentes composições litológicas, com o predomínio do Grupo Serra da Mesa, Unidade Xisto Quartzitica, com quartzitos que apresentam acamamento definido, e são, em geral, friáveis com variadas proporções de muscovita. As áreas são planas ou quase planas e margeiam o rio das Almas e seus afluentes que são, em geral, de porte considerável e desprovidos de áreas alagadiças expressivas.

As condições edafoclimáticas favorecem o desenvolvimento da vegetação ciliar próximo aos canais de drenagem, embora esta esteja quase que completamente ausente em alguns trechos. Destacam-se nessa unidade os Latossolos Vermelhos distrófico, textura argilosa em relevo suave ondulado e Latossolos Vermelho-Amarelos típico, textura média, em relevo plano ou quase plano em que predominam as pastagens na porção centro-sul, seguidas das culturais anuais e plantações da cana de açúcar na porção centro-norte.

Os Latossolos principalmente o Latossolo Vermelho, de modo geral, apresentam reduzida suscetibilidade à erosão, boa permeabilidade e drenabilidade e a baixa relação textural B/A (pouca diferenciação no teor de argila do horizonte A para o B) que garantem, na maioria dos casos, uma boa resistência desses solos à erosão. No entanto, esse compartimento apresenta 172 feições erosivas lineares, que representam $76,10 \%$ das feições identificadas na área da bacia hidrográfica do rio das Almas, na microrregião de Ceres. Esses focos erosivos em sua maioria ocorrem em áreas de pastagem, ou seja, o pisoteio de gado formando sulcos, favorecem o escoamento concentrado, aliado a intensidade e totais de chuva, forma, declive e comprimento das vertentes, falta de cobertura vegetal, compactação dos solos, além da insuficiência de práticas conservacionistas, propiciam a ocorrência de processos erosivos lineares.

Nesse compartimento, devido elevado número de focos erosivos, foi selecionada uma área para estudos de detalhe - a Fazenda Badega (figura 7) - com o levantamento dos sistemas pedológicos por meio de transecto topográfico para coleta de amostras de solo (BOULET, 1988). Nos trabalhos de morfopedologia quanto em estudos relacionados a solos de forma geral, é usual a representação gráfica de sistemas pedológicos nas vertentes na forma bidimensional com base nas topossequências. Para tanto, foram utilizadas ferramentas em ambiente SIG para representar tridimensionalmente os principais sistemas pedológicos da área de estudo.

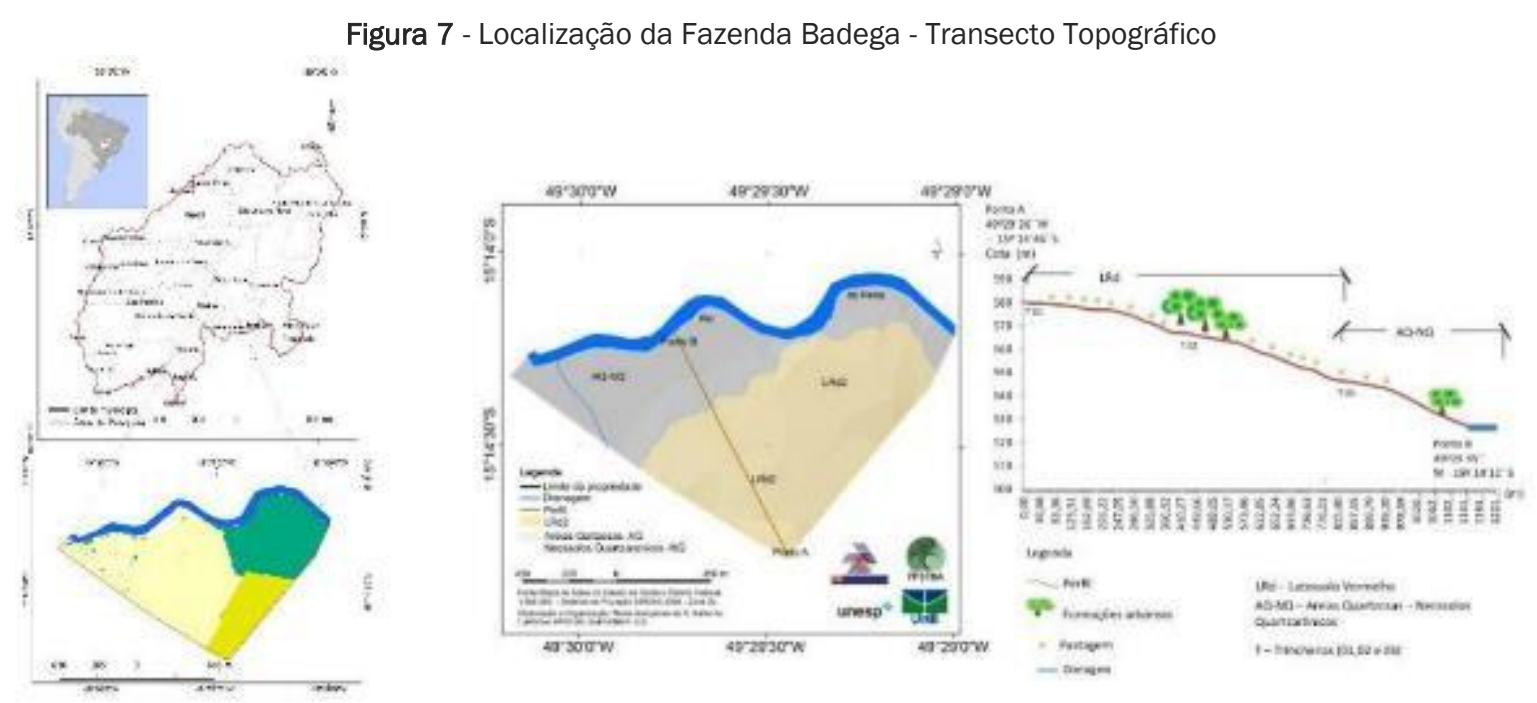

Fonte: Autores (2017). 
Nesta etapa foram elaborados mapas preliminares de declividade (a), hipsometria (b) e solo (c) da área da Fazenda Bagega, indicando detalhe para definição dos pontos de coleta de solos com abertura de 5 trincheiras (figura 8).

(a)

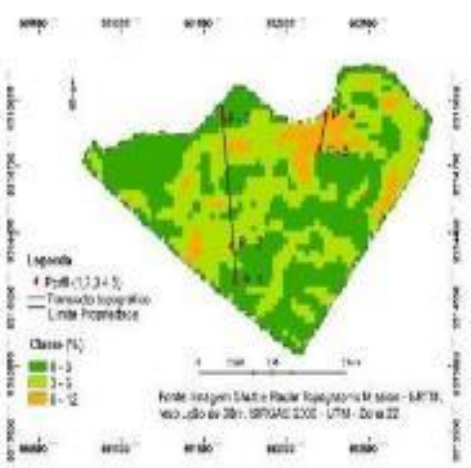

Figura 8 - Mapa de declividade (a), hipsometrico (b) e solo (c)

(b)

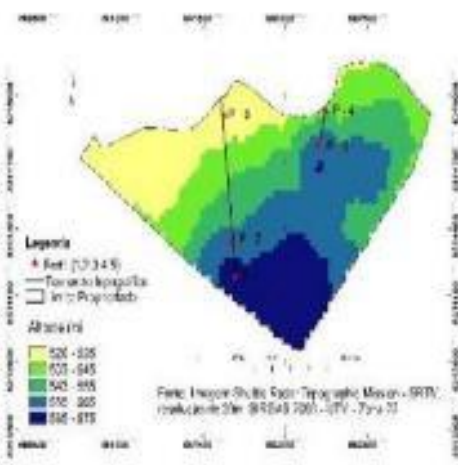

Fonte: Autores (2017). (c)

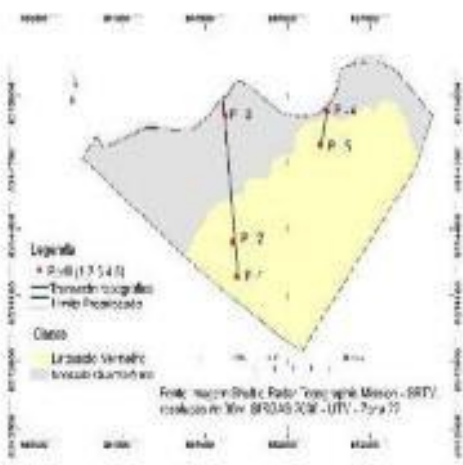

A caracterização dos atributos físicos, químicos e biológicos dos solos na área de estudo foram realizados por meio de análises em campo (figura 9) e em laboratório.

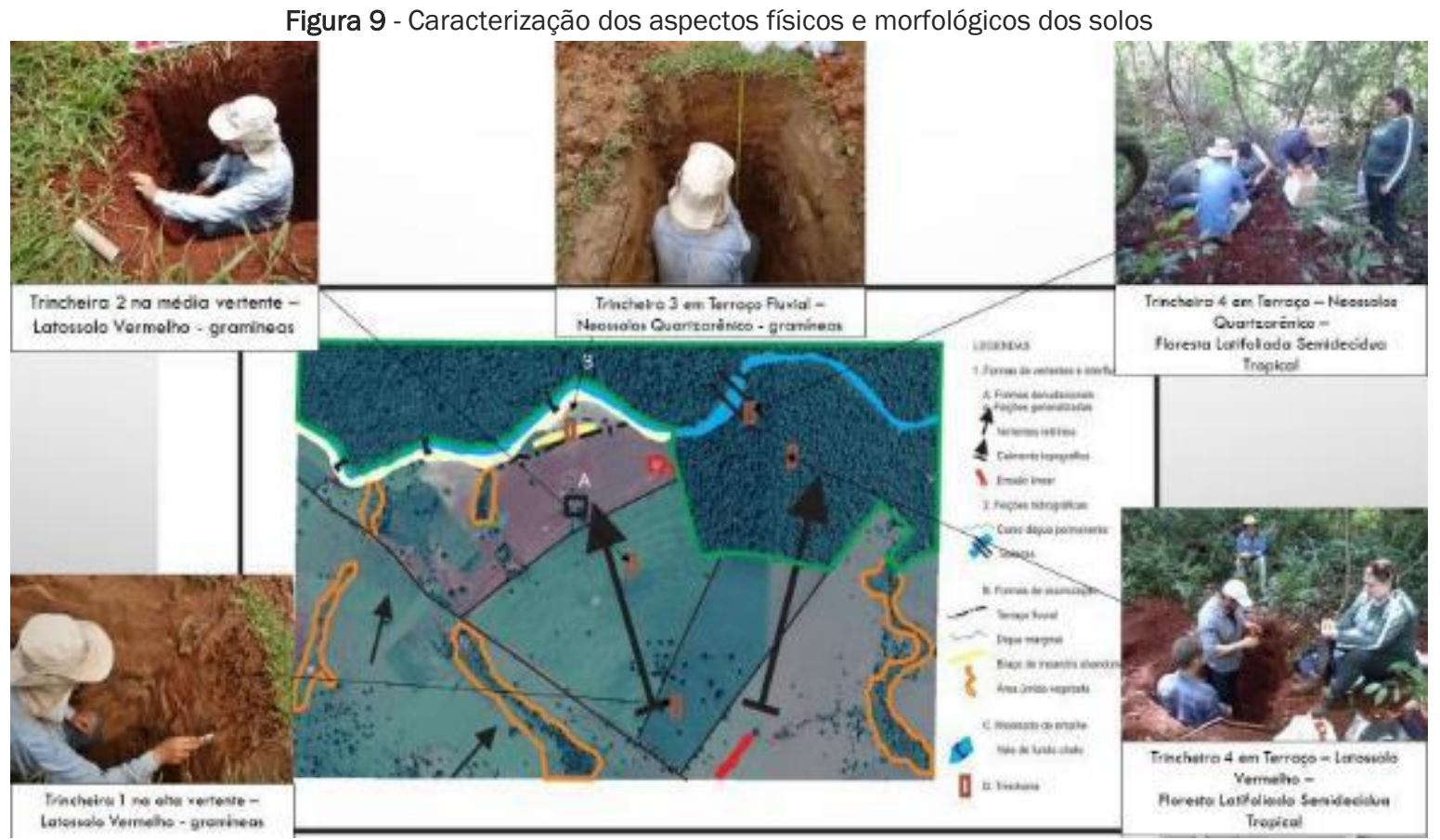

Fonte: Autores (2017).

Estas análises permitiram identificar as características de textura, estrutura, porosidade e fertilidade, enquanto indicadores importantes dos solos. Também, foram analisados os dados de densidade do solo adquirido por meio dos anéis volumétricos e que auxiliam no entendimento de processos como a compactação do solo. 
No sistema pedológico identificado na Fazenda Badega formado por Latossolo Vermelho/Neossolo Quartzarênico verificou-se na área rebaixada, com rampas longas, cobertas com pastagem, associados aos Neossolos Quartzarênicos, a ocorrência de erosão linear do tipo ravina. Esses terrenos apresentam baixo grau de coesão e ocupam principalmente os terços médios e inferiores das vertentes, locais em que o nível d'água se encontra não muito abaixo da superfície, o que propicia baixa capacidade de suporte, constituindo em áreas frágeis a ocupação antrópica (Salomão, 2010). Esta dinâmica pode ser observada no esboço pedomorfológico (figura 10), onde foram delimitadas as unidades elementares do relevo que condicionam o comportamento hidrológico das águas superficiais e subsuperficiais, com destaque para os solos, a geologia e a morfologia do relevo

Figura 10 - Abertura de cinco trincheiras

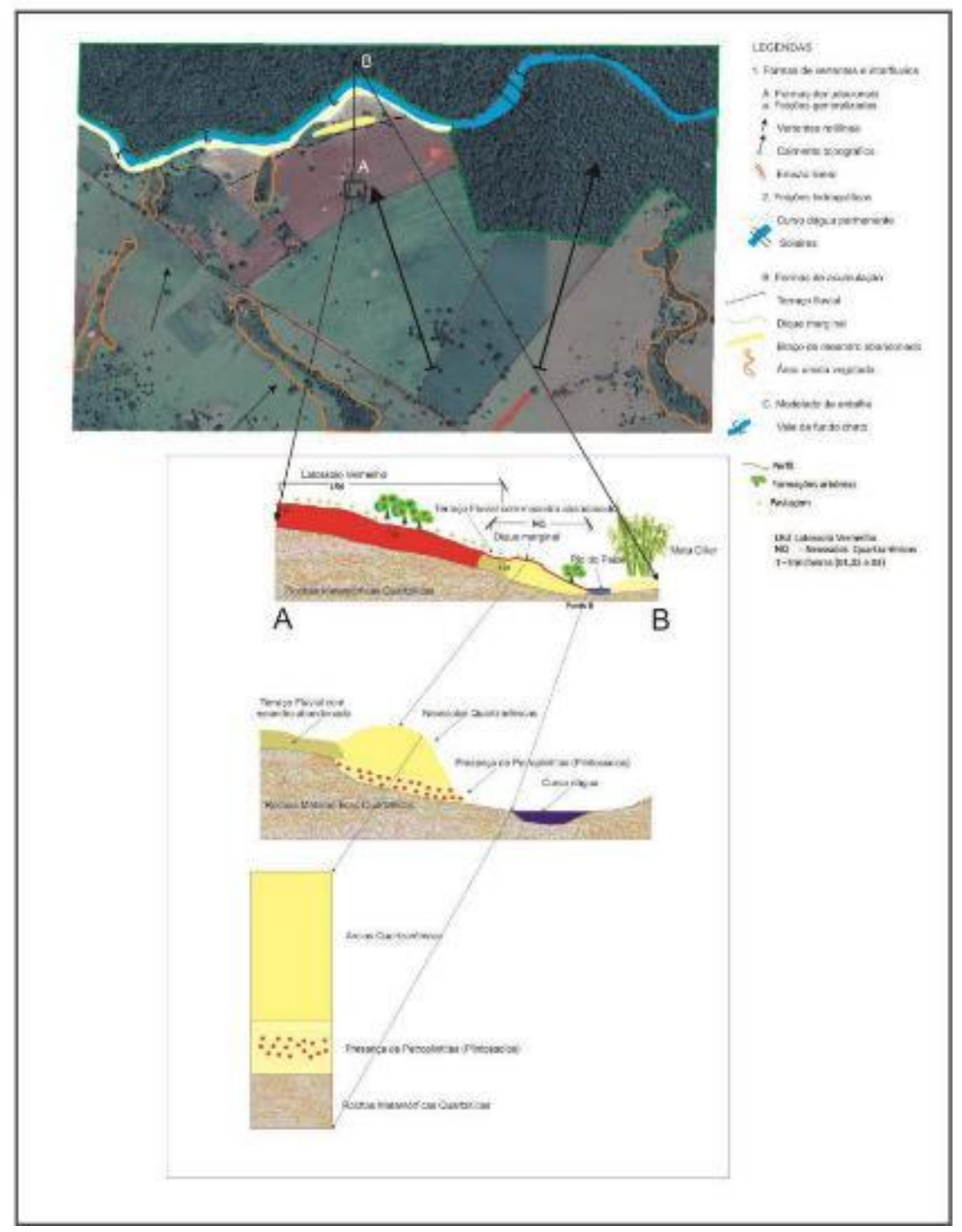

Fonte: Autores (2017).

Associado aos aspectos pedológicos, realizou -se a identificação da Macrofauna edáfica, composta por espécies que apresentam sensibilidade aos impactos dos diferentes tipos de solo e vegetação, sendo a sua diversidade diretamente influenciada pelas práticas de manejo que estimulam a dinâmica da matéria orgânica deste solo. 
Os sistemas analisados apontaram diversidades semelhantes em relação à ordem dos indivíduos. Entretanto, quando considerado o gênero, a diversidade foi significativamente maior no Sistema/trincheira 3 - próximo ao curso d'água (representados por 14 gêneros), sendo que os Sistema/trincheira 4 e 5 - vegetação nativa, apresentaram diversidades semelhantemente altas (com 13 gêneros cada). A menor diversidade foi encontrada nos Sistema/trincheira 1 e 2, ambos compostos por seis gêneros;

b) Compartimento MP-II: O menor compartimento representando 14,64\% da área da bacia. Localiza-se nas porções Nordeste/Leste da área. Predomina o Complexo Barro Alto, este Complexo, juntamente com o de Niquelândia e de Cana Brava, constituem as maiores intrusões acamadadas máfico-ultramáfico de filiação toleítica do Brasil, representando uma das principais áreas para a exploração/explotação de níquel laterítico e cobre, além de apresentar áreas mineralizadas para elementos do grupo da platina (EGP). Destaca-se ainda a caracterização de importantes depósitos de bauxita associados às rochas anortosíticas do complexo. São áreas moderadamente onduladas e predominam os Cambissolos em sua maioria com pastagem e cobertura vegetal natural, seguido da cultura e cana de açúcar. Foram identificados oito focos erosivos lineares;

c) Compartimento MP-III: O segundo maior compartimento se localiza de norte a sul na porção oeste e representa 25,80\% da área. Predomina o Granodiorito Águas Claras - consiste no conjunto acamadado de olivina gabros coroníticos, troctolitos, anortositos e anfibolitos granadíferos. O relevo, na maior parte, é plano a suave ondulado com algumas áreas moderadamente a forte ondulado. O solo representativo é Argissolo, que costumam ser bastante suscetíveis à erosão linear pelo forte gradiente textural que apresentam e pelo relevo um pouco mais movimentado. Foram pontuados 19 focos erosivos. A pastagem ocupa pouco mais de 56\% do compartimento seguido da cobertura vegetal natural com 37,07\%;

d) Compartimento MP-IV: Ocupa 19,29\% da área na porção centro-oeste. A geologia caracterizase pelo predomínio da suíte Intrusiva Itapuranga compostas de granitos, granodioritos e tonalitos, alguns com anfibólio sódico e clinopiroxênio, entre outros. Predominam os Latossolos Vermelhos em relevos planos a suave ondulado, com a ocorrência de 27 focos erosivos em área predominantemente de pastagem, que domina esse compartimento seguido da cana de açúcar.

\section{CONSIDERAÇÕES FINAIS}

O conhecimento do padrão de organização e da estrutura da paisagem da bacia hidrográfica do rio das Almas, no domínio do Bioma Cerrado, evidencia os desmatamentos, a extinção de fauna e flora e sobreleva a importância de se preservar os fragmentos da vegetação natural que ainda ocorrem na área, bem como os ecossistemas a eles associados.

Algumas unidades de paisagem identificadas durante trabalho de campo, mostraram fragmentos de formações florestais ainda preservados em as áreas marginais de cursos de água. Essas áreas configuram paisagens aptas à conservação e ao estabelecimento de corredores ecológicos e contam com Legislação protetiva.

Em áreas com limitações a ocupação, com declives elevados, observou-se fragmentos das formações florestais e savânicas, principalmente nos CMP II, III e IV. Já o CMP I, localizado na área central da bacia hidrográfica, em que predominam os Latossolos Vermelhos, apresenta a maioria dos focos erosivos identificados na área da bacia hidrográfica do rio das Almas, principalmente em áreas de pastagem, em decorrência de fatores naturais e antrópicos. 
As análises realizadas no estudo, permitiram identificar e caracterizar unidades de paisagens e compartimentos morfopedológicos, bem como ressaltar a importância dessas áreas e suas características para o planejamento de uso e ocupação das terras.

\section{REFERÊNCIAS}

BARBALHO, M.G.S. Avaliação dos efeitos do desmatamento nos solos e nos recursos hídricos na bacia do rio das Almas, microrregião de Ceres (GO). Relatório de Pós-Doutorado - PROCAD/CAPES - Novas Fronteiras no Oeste: Relação entre sociedade e natureza na microrregião de Ceres em Goiás (1940-2013). UNB/CDS, 2017.

BARBALHO, M.G.S.; DUTRA, S.S.; DELLA GUISTINA, C.C. Avaliação Temporal do Perfil da Vegetação da Microrregião de Ceres através do Uso de Métricas de Paisagem. Boletim Goiano de Geografia, v. 35 n.3 set-dez. Goiânia, 2015.

BECKER C; OSTERMAN, J; PAHL, M. Automatic quality assentamento of gis data base an object coherence. In: Procedings of the 4th GEOBIA. Rio de janeiro [s/n], 2012.

BLASCHKE T. \& KUX H. Sensoriamento Remoto e SIG Avançados: novos sistemas sensores métodos inovadores. São Paulo: Oficina de Textos, 2005.

BLASCKE, T; HAY, G. J; KELLY, M.; LANG, S.; HOFMANN, P; ADDINK, E; FEITOSA, R. Q; MEER, F. V. WERFF, H. J; COILLIE, F. V; TIEDE, D. Geographic Object-Based Image Analysis - Towards a new paradigman. ISPRS Journal of Photogrammetry and Remote Sensing, v. 87, pp.180-1091, 2014.

BOULET, R. (1988). Análise estrutural da cobertura pedológica e cartografia. In: Congresso Brasileiro de Ciência do Solo, 21, Campinas. Anais... Campinas: SBCS. p. 79-90.

CARDOSO, M. R. D.; MARCUSO, F.F. N.; BARROS, J.R. Classificação climática de Koppen-Geiger para o Estado de Goiás e o Distrito Federal. Acta geográfica, v.8 n. 16, jan./mar., 2014. pp.44-55.

CASTRO, S. S. \& SALOMÃO, F. X. de T. Compartimentação Morfopedológica e sua Aplicação: Considerações Metodológicas. São Paulo/SP. Revista GEOUSP, N 7, p. 28 - 35. São Paulo: USP, 2000.

CIANCIARUSO, M. V.; BATALHA, M. A.; SILVA, I. A. Seasonal variation of a hyperseasonal Cerrado in Emas national park, central Brazil. Flora 200: 2005, pp. 345-353.

DUTRA E SILVA, Sandro. No Oeste, a terra e o céu: a expansão da fronteira agrícola no Brasil Central. Rio de Janeiro: Mauad X, 2017

EMBRAPA. Centro Nacional de Pesquisa de Solo. Sistema Brasileiro de Classificação de Solos: $3^{a}$ ed. Rio de Janeiro: Embrapa Solos, 2013.

FAISSOL, S. O Mato Grosso de Goiás. Rio de Janeiro: IBGE, 1952.

Instituto Brasileiro de Geografia e Estatística (IBGE): Manual Técnico do Uso da Terra. $3^{a}$ Ed. Rio de Janeiro. 2013.

LACERDA FILHO, J. V. de; FRASCA, A. A. S. Compartimentação Geotectônica. In: Geologia do Estado de Goiás e Distrito Federal. Programa Geologia do Brasil: Integração, Atualização e Difusão de Dados da Geologia do Brasil. Goiânia: CPRM/SIC-FUNMINERAL, 2008.

MAMEDE, L.; NASCIMENTO, M.A.L.S.; FRANCO, M. Geomorfologia, In. Projeto RADAMBRASIL. Folha SD 22 Goiás. Rio de Janeiro, 1981 (Levantamento de Recursos naturais, 25).

RAMALHO FILHO, A.; BEEK, K. J. Sistema de avaliação da aptidão agrícola das terras. $3^{a}$ ed. Rio de 
Janeiro: EMBRAPA-CNPS, 1995.65p.

RIBEIRO, J.F.; WALTER, B. M. T. Fitofisionomias do bioma Cerrado. In: SANO S.M; ALMEIDA S. P. Eds. Cerrado: Ambiente e Flora. Planaltina: EMBRAPA - CPAC. 1998. P.89-168.

SALOMÃO, F. X. de T. Controle e prevenção dos processos erosivos. In: GUERRA, A. J. T.; SILVA, A. S. da; BOTELHO, R. G. M. erosão e conservação dos solos: conceitos, temas e aplicações. Rio de Janeiro: Bertrand Brasil, 2010. p. 229-268.

SILVA, A. A; MIZIARA, F. Avanço da fronteira do setor sucroalcooleiro e expansão da fronteira agrícola em Goiás. Pesquisa Agropecuária Tropical, vol. 41, nº 3, jul/set, 2011, p. 399-407. Universidade Federal de Goiás, Goiás.

TURNER, M. G. Landscape ecology: the effect of pattern on process. Annual review of Ecology and Systematics, n.20, p.171-197, 1989.

WAIBEL, L. Vegetação e Uso da Terra no Planalto Central. Revista Brasileira de Geografia, v.10.n.3 1948.

\section{Agradecimentos}

Ao apoio da Coordenação de Aperfeiçoamento de Pessoal de Nível Superior (CAPES) e do Programa Nacional de Cooperação Acadêmica (PROCAD) entre a UNESP, UnB e UniEVANGÉLICA a partir do Projeto intitulado "Novas fronteiras no Oeste: relação entre sociedade e natureza na Microrregião de Ceres em Goiás (1940-2013)” - Processo n² 2980/2014. 